\title{
The Solvent Extraction of Cadmium from Phosphoric Acid Solution By 3-methyl-quinoxaline-2-thione in Toluene as Diluent
}

\author{
SANAE BAKI SENHAJI ${ }^{1 *}$, AHMED ELYAHYAOUI ${ }^{1}$, \\ SAIDATI BOULASSA ${ }^{1}$ and EL MOKHTAR ESSASSI ${ }^{2}$ \\ 'Laboratoire de Radiochimie, Departement de Chimie, Faculte des Sciences- Rabat, Morocco. \\ 2Laboratoire de Chimie Organique heterocyclique, Faculte des sciences, Rabat, Morocco. \\ *Corresponding author E-mail: b.senhaji.sanae @ gmail.com
}

http://dx.doi.org/10.13005/ojc/320624

(Received: October 22, 2016; Accepted: November 25, 2016)

\begin{abstract}
The solvent extraction of cadmium (II) from phosphoric acid 2.5M by 3-methyl-2 (1H)quinoxaline-thione $\left(\overline{L H} \equiv \mathrm{C}_{9} \mathrm{H}_{8} \mathrm{~N}_{2} \mathrm{~S}\right)$ is investigated in various experimental conditions. Obtained results show a variation of extraction of $\mathrm{Cd}$ with $\mathrm{pH}$, and $\overline{L H}$ concentration. The conventional methods of slope analysis can't be performed successfully for understanding interaction mechanisms. A technique combining slope analysis with the variation of overall extraction constant with $\mathrm{pH}$ is performed in this case. There is no predominant removal mechanism, cadmium is extracted as complexes in $\mathrm{Cd}: \overline{\mathrm{LH}}: \mathrm{H}_{3} \mathrm{O}^{+}\left(\mathrm{OH}^{-}\right)$stoichiometry varying between 1:1:0 and 1:3:3. The extraction reaction is a complex process including ion exchange-ion pair formation, organic and inorganic complexation, $\mathrm{H}_{3} \mathrm{PO}_{4}$ deprotonation and solvatation phenomena. A best recovery of 43 to $60 \%$ is achieved in acidic conditions with $\mathrm{C}_{\mathrm{LH}}=0.26 \mathrm{M}$.
\end{abstract}

Keywords: Cadmium, Extraction, Phosphoric medium, pH, 3-methyl-2 (1H)-quinoxaline-thione.

\section{INTRODUCTION}

Due to their harmful effects, heavy metals are a major threat to ecological environment, food safety and agriculture sustainable development. As a result, these elements are not suitable in nature that various measures are undertaken to control, and prevent their presence in environment. Among these heavy metals, cadmium is listed as the seventh most toxic substances ${ }^{1-2}$.
Enrichment of $\mathrm{Cd}$ in soils is reporte through the land application of bio solids, industrial eûuents, and Cd-rich phosphate fertilizers ${ }^{3}$. In general, phosphate fertilizers are produced by the acidulation of crushed and powdered phosphate.

Thus the removal of $\mathrm{Cd}$ (II) from phosphoric acid which is the intermediary product for the production of all high grade phosphate fertilizers, is of ever-increasing interest. Several methods including 
precipitation, solvent extraction and ion exchange are proposed in this case.

Amine compounds are successfully used for cadmium separation from complex aqueous media. However, in this extraction system, metal extraction is carried out from acidic media, so that the amine in the organic phase is first converted to its salt. To avoid this limitation on the aqueous condition, quaternary ammonium salts, is employed in neutral, and slightly alkaline. As known the sulfhydryl-containing compounds have the ability to chelate heavy metals such cadmium that Chelating exchangers with thiol functional groups are used for $\mathrm{Cd}$ (II) removal from aqueous solutions ${ }^{4-5}$.

Recently the use of extractants with a bifunctional groups such as quinoxaline-thione for zinc and cadmium removal are highlighted as potential extractant for metal removal from complex aqueous media ${ }^{6-7}$.

The advantage of this process is that can combine organic and inorganic complexing phenomena, ion-pair formation and ion exchange reactions. Thus, cadmium removal from $\mathrm{H}_{3} \mathrm{PO}_{4} 3.22$ $\mathrm{M}$ is successfully achieved over wide range of $\mathrm{pH}$, in this case. Understanding interaction mechanisms involved in this case, is essential and allows efficient use of solvent extraction procedure ${ }^{8}$.

This interaction is also an actual problem of modern analytical chemistry, which is primordial for environmental sciences, as well as geology, clinical and medicinal chemistry, as discussed previously ${ }^{9}$.

Unfortunately, it is reported that $\mathrm{Cd}(\mathrm{II})$ extraction by amines is a variable phenomenon when inorganic complexation is involved in aqueous phase that slope analysis cannot be used to carry out extraction stoechiometry ${ }^{10}$. Similar results are obtained for this metal in phosphoric medium ${ }^{7}$. To determine extracted species, a technique combining slope analysis with the variation of apparent extraction constant with $\mathrm{pH}$ is performed, in this case. As shown, cadmium removal is essentially achieved via anion-exchange. Obviously to control extraction process in question, more informations are required for the removal of $\mathrm{Cd}$ with analytical concentration variation of $\mathrm{H}_{3} \mathrm{PO}_{4}$.
For these reasons the present study aims to carry out cadmium extraction reaction predominating in $\mathrm{H}_{3} \mathrm{PO}_{4} 2.5 \mathrm{M}$.

\section{MATERIAL AND METHODS}

\section{Reagents}

All reagents used: $\mathrm{Cd}\left(\mathrm{NO}_{3}\right)_{2}, \mathrm{HCl}, \mathrm{NaOH}$, and $\mathrm{H}_{3} \mathrm{PO}_{4}$ are of analytical grade and used without further purification. Stock solutions $\left(10^{-3} \mathrm{~mol} / \mathrm{l}\right)$ of $\mathrm{Cd}$ (II) are prepared by dissolving known amount of cadmium nitrate in adequate volume of $0.1 \mathrm{M}$ laboratory phosphoric acid. Initial $\mathrm{pH}$ of the aqueous phases, is adjusted using $0.1 \mathrm{M} \mathrm{KOH}$ or $0.1 \mathrm{M} \mathrm{HNO}_{3}$, and measured before and after extraction test.

\section{Procedure}

The organic and aqueous solutions $\left(\mathrm{H}_{3} \mathrm{PO}_{4}\right.$ $2.5 \mathrm{M}$ ) were equilibrated in $20 \mathrm{ml}$ separator funnel with an organic/aqueous ratio of 1:1 (5 ml organic solution and $5 \mathrm{ml}$ aqueous solution) which is shaken vigorously for $15 \mathrm{~min}$. Preliminary tests have shown that equilibrium of extraction is reached in less than $5 \mathrm{~min}$. After equilibration, the separator funnel is left standing for at least $30 \mathrm{~min}$ for completing phase separation. After equilibration, the separator funnel is left standing for at least $30 \mathrm{~min}$ for completing phase separation. The synthesis of 3-methyl-2 $(1 \mathrm{H})$ quinoxaline-thione $\left(\mathrm{C}_{9} \mathrm{H}_{8} \mathrm{~N}_{2} \mathrm{~S}\right)$ designated thereafter as $\overline{L H}$, is performed as described previously ${ }^{6-7}$. A solution of synthesized extractant is prepared with dissolution of $0.26 \mathrm{~mol} / \mathrm{l}$ of $\overline{L H}$ in toluene $\left(\mathrm{C}_{7} \mathrm{H}_{8}\right)$.

The extraction of cadmium is studied from aqueous phosphoric acid solutions (2.5M) containing $10-4 \mathrm{M} \mathrm{Cd}(\mathrm{II})$. All the extraction experiments were carried out at room temperature.

The $\mathrm{Cd}(\mathrm{II})$ concentrations in the aqueous phase $\left(\left(\left[\mathrm{Cd}^{2+}\right]\right)\right)$ were determined using Benchtop XRF Spectrometer with X-LabPro Version 4.0 software. while the concentration of cadmium in the organic phase ( $[\overline{c d}]$ ) was calculated from material balance.

The distribution ratio, $\mathrm{D}$, is calculated as follows:

$$
D=\frac{[C d]}{\left[C d^{2+}\right]}
$$




\section{RESULTS AND DISCUSSION}

\section{Effect of equilibrium $\mathrm{pH}$}

Fig. 1 reproduces the logarithmic variation of $\mathrm{D}$ with $\mathrm{pH}$ for $\mathrm{H}_{3} \mathrm{PO}_{4} 2.5 \mathrm{M}$, in the $\mathrm{pH}$ range of about 1.7 to 7.0 , and analytical ligand concentration ( $\left.C_{L H}\right)$ of $0.05,0.13,0.26$, and $0.62 \mathrm{M}$. As can be seen, extraction of cadmium increases with increase in $\mathrm{pH}$ to reach a maximum value at $\mathrm{pH}=2.1$, and after a steady stage observed in the $\mathrm{pH}$ range 2.1 3.4, $\log \mathrm{D}$ increases as $\mathrm{pH}$ continue to rise. Maxima are found at $\mathrm{pH} 3.7$ and 4.5 , in this case. Extraction yield higher than $66 \%$ is achieved at $\mathrm{C}_{\mathrm{Lr}}=0.62 \mathrm{M}$, for $\mathrm{pH}$ ranging from 2.0 to 5.0. As discussed previously, distinct $\mathrm{pH}$ segments with continuous varying slopes suggest that cadmium extraction rises from different reactions ${ }^{7}$.

\section{Effect of extractant concentration}

Fig. 2 reproduces the logarithmic variation of $D$ with $C_{L H}$ at different $\mathrm{pH}$ values, for $\mathrm{H}_{3} \mathrm{PO}_{4}$ $2.5 \mathrm{M}$.

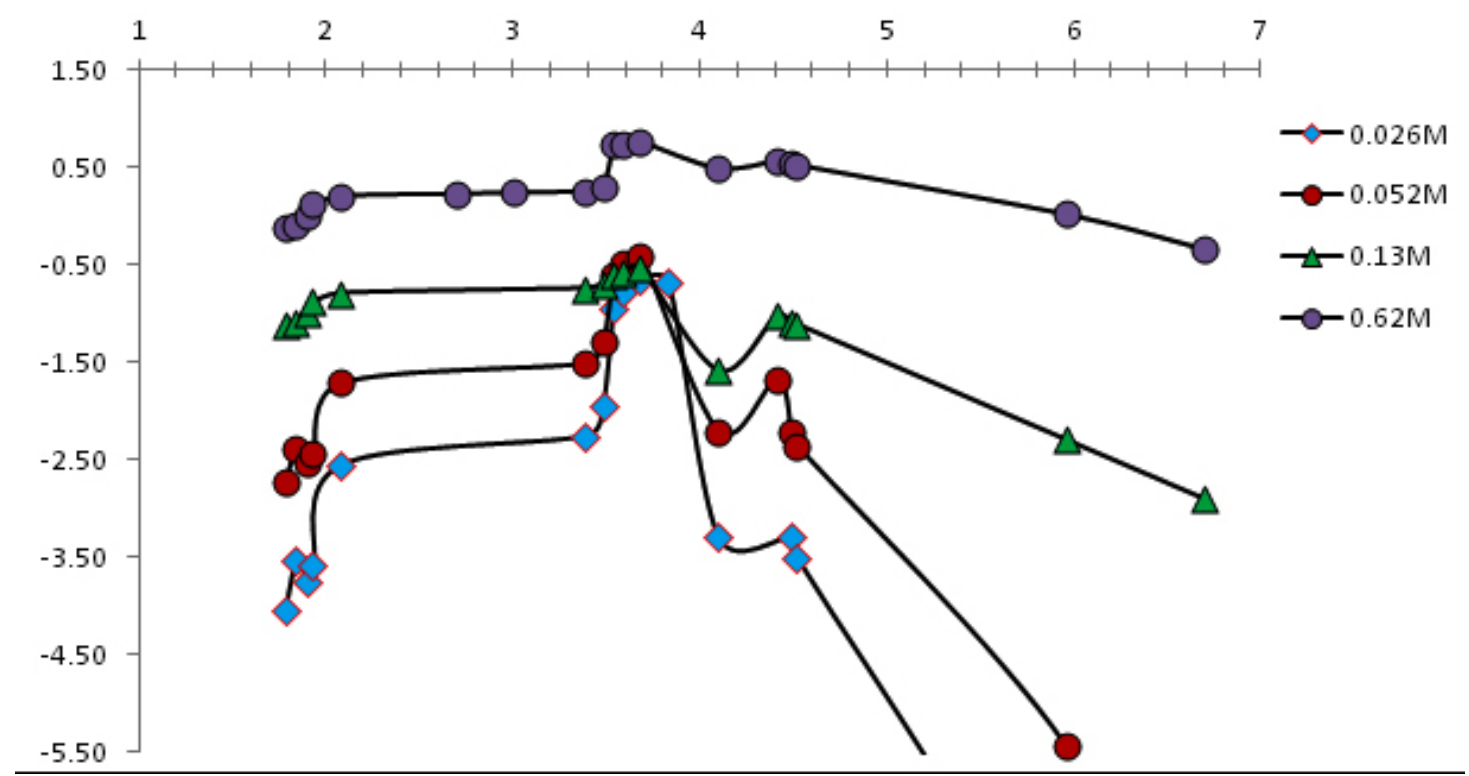

Fig. 1: Variation of log $\mathrm{D}$ versus $\mathrm{pH}$, at $C_{L F}$ of $0.05,0.026 \mathrm{M}, 0.13$, and $0.62 \mathrm{M}$, in $2.5 \mathrm{M} \mathrm{H}_{3} \mathrm{PO}_{4}$

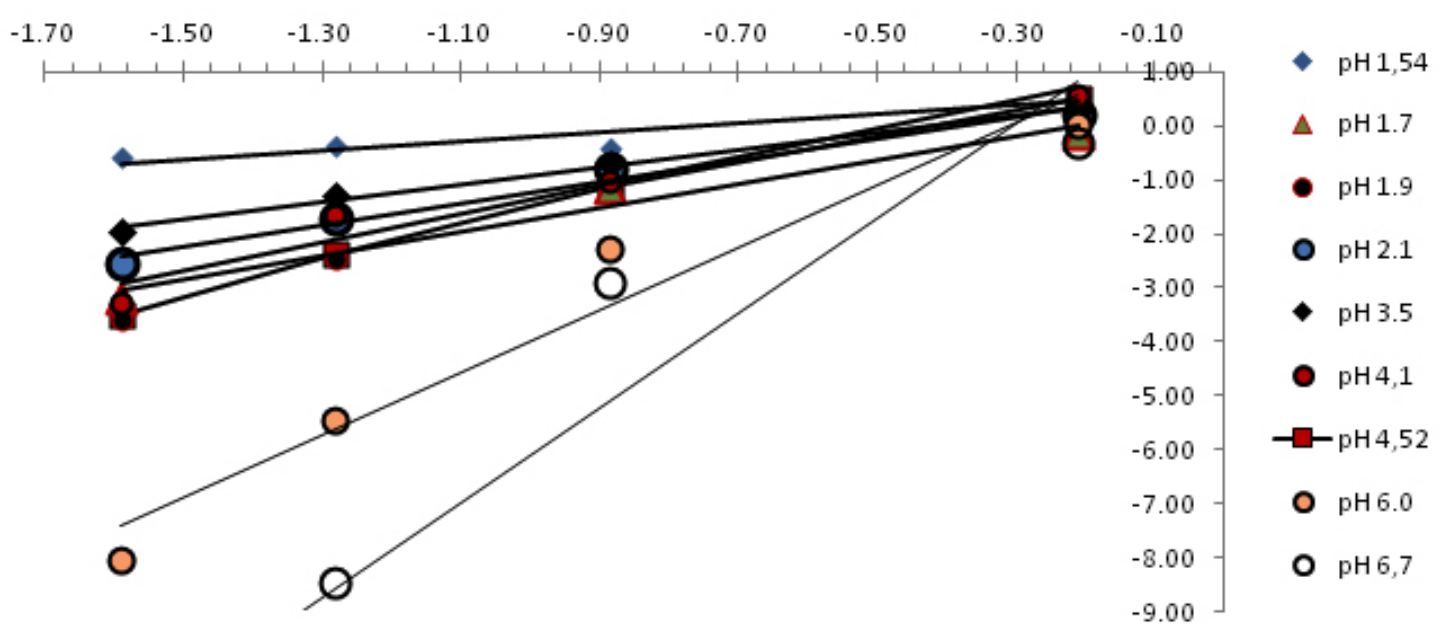

Fig. 2: Variation of $\log D$ with the $\mathrm{LH}$ analytical concentration $C_{L H}$, at $\mathrm{CH}_{3} \mathrm{PO}_{4}=2.5 \mathrm{M}$, for $\mathrm{pH}$ value ranging from 1.5 to 6.7 
As found, these variations are linear with slopes varying in the range of about 1 to 6 . The overall stoechiometry extraction reaction is not an integer as could be expected from theoretical single reaction. This indicates a variation of extraction of $\mathrm{Cd}$ with $\mathrm{pH}$, and $\mathrm{LH}$ concentration. Similar

Table 1: Equilibrium logarithmic constants $\left(\log \mathrm{K}_{\mathrm{In}}\right)$ of cadmium extraction

by 3-Methyl Quinoxaline-2-thione from $\mathrm{H}_{3} \mathrm{PO}_{4}$ 2.5M. . (* Calculated constant)

\begin{tabular}{|c|c|c|c|}
\hline$(I ; n)$ & $\log K_{l n}$ & $(I ; n)$ & $\log K_{l n}$ \\
\hline$(2.71 ; 1.01)$ & -1.06 & $(1 ; 1)$ & $2.71^{*}$ \\
\hline$(2.68 ; 1)$ & -0.89 & $(1 ; 2)$ & $-6.73^{*}$ \\
\hline$(2.68 ; 1.83)$ & -2.58 & $(1 ; 3)$ & $-8.79^{\star}$ \\
\hline$(2.68 ; 2.88)$ & -4.60 & $(2.74 ;-0.57)$ & 1.50 \\
\hline$(2 ; 0.04)$ & 0.66 & $(2.74 ;-1.71$ & 8.92 \\
\hline$(1.6 ; 0.04)$ & 0.54 & $(2.74 ;-2.86$ & 14.08 \\
\hline$(1,6 ; 0.56)$ & $-1,27$ & $(3 ;-0.57)$ & 3.82 \\
\hline$(1.6 ; 2.36)$ & $-7,54$ & $(3 ;-1.7$ & 8.93 \\
\hline$(2 ; 1)$ & $0.76^{*}$ & $(3 ;-2.8)$ & 13.90 \\
\hline$(2 ; 2)$ & $-5.63^{\star}$ & $(3,0)$ & $1.23^{*}$ \\
\hline$(2 ; 3)$ & $-13.66^{\star}$ & $(3,1)$ & $-1.72^{*}$ \\
\hline$(2,-1)$ & 4.53 * & $(3,2)$ & $-0.73^{*}$ \\
\hline$(2,-2)$ & $8.12^{*}$ & $(3,3)$ & $-1.67^{*}$ \\
\hline$(2,-3)$ & $10.53^{\star}$ & $(3,-1)$ & $5.8^{*}$ \\
\hline$(1.0 ; 0.0)$ & 0.77 & $(3,-2)$ & $10.3^{*}$ \\
\hline$(1.0 ; 2.2)$ & -7.12 & $(3,-3)$ & $14.8^{*}$ \\
\hline$(1 ; 0.75)$ & -2 & $(1 ; 2)$ & $-6.73^{\star}$ \\
\hline$(1 ; 1.5)$ & -4.76 & $(1 ; 3)$ & $-8.79^{\star}$ \\
\hline
\end{tabular}

results are observed previously for the extraction of cadmium, zinc and some rare earths by various chelatants $^{6-7 ; 10-14}$. This shows that at least, two predominant extracted complexes are involved in the removal of $\mathrm{Cd}$ (II), in this case.

\section{Cadmium extraction from phosphoric acid solutions}

From results obtained previously for $\mathrm{Cd}(\mathrm{II})$ removal by 3 -methyl-quinoxaline-2-thione ${ }^{6-7}$, the extraction equilibrium from phosphoric media may be written in the general forms:

$$
\begin{aligned}
& C d^{2+}+l\left(\overline{L H_{2}^{+} X^{-}}\right) \leftrightarrows C d\left(L H_{2}\right)_{l}(X)_{l}^{2+}: K_{l 0} \\
& C d^{2+}+L\left(\overline{L H_{2}^{+} X^{-}}\right)+n H_{2} \mathrm{O} \leftrightarrows \\
& C d\left(L H_{2}\right)_{l}(X)_{l} H_{-n}^{(2-n)+}+n H_{3}^{+}: K_{l n}
\end{aligned}
$$

Where $X^{-}$is aqueous anionic ligand, the onlined entities refer to organic phase, and $n=0 ; 1 ; 2$, etc....The symbol $\mathrm{H}_{-n}$ stands both for hydrogen $(n<0)$ and for $\mathrm{OH}$ group $(n>0) . \mathrm{K}_{I n}$ denotes the constant of equilibrium reaction. The extracted species are given by:

$$
[\overline{C d}]=\left[\overline{C d\left(L H_{2}\right)_{2} L(X)_{l}^{2+}}\right]+\left[C d\left(L H_{2}\right)_{2} L(X)_{l} H_{-n}^{(2-n)+}\right]
$$

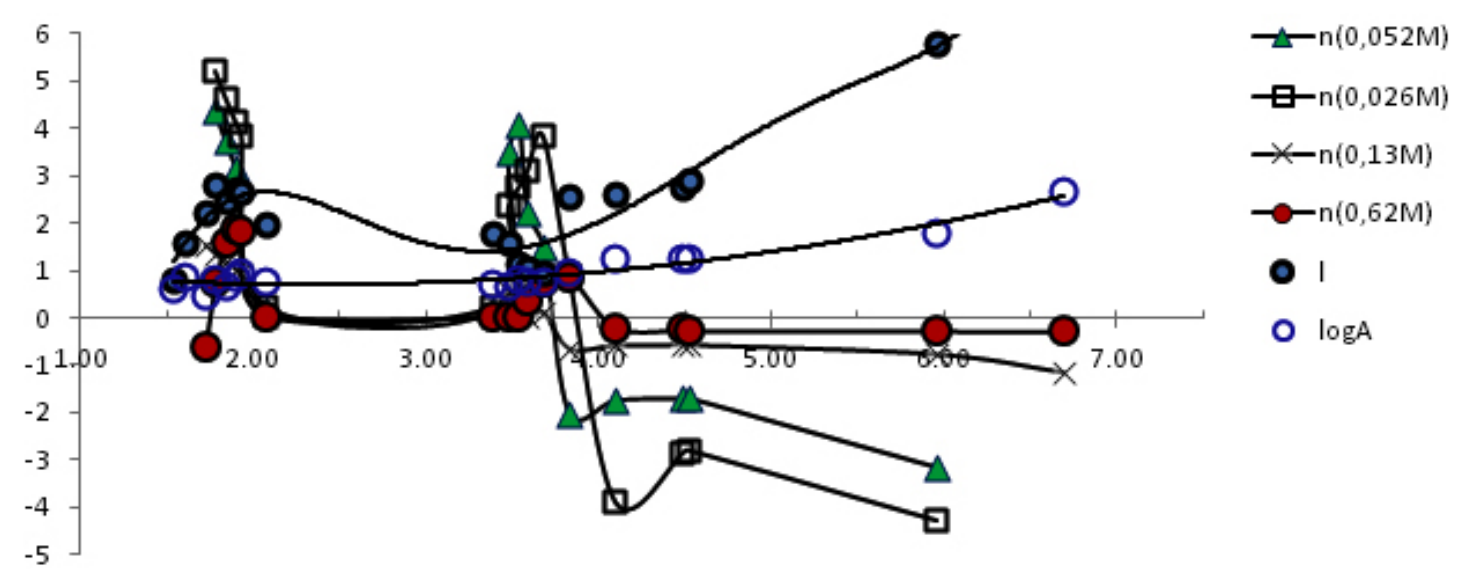

Fig.3: Variations of $\mathrm{I}, \mathrm{n}$, and $\mathrm{A}$ versus $\mathrm{pH}$, obtained for $\mathrm{H}_{3} \mathrm{PO}_{4} 2.5 \mathrm{M}$, at $C_{\text {LR }}=0.026,0.052,0.13$, and $0.62 \mathrm{M}$. 
$\mathrm{K}_{l 0}=\frac{\left\lfloor\overline{C d\left(L H_{2}\right)_{2} L(X)_{l}^{2+}}\right]}{\left[C d^{2+}\right]\left[\overline{L H_{2}^{+} X^{-}}\right]^{l}}$

and

$\mathrm{K}_{l n}=\frac{\left[\overline{C d\left(L H_{2}\right)_{2} L(X)_{l} H_{-n}^{(2-n)+}}\right]\left[H^{+}\right]^{n}}{\left[C d^{2+}\right]\left[\overline{L H_{2}^{+} X^{-}}\right]^{l}}$

Assuming in first approximation that

$[\overline{C d}]<C_{L H}$, which results in $\left[\overline{L_{2}^{+} X^{-}}\right]=C_{L R}$ we obtain:

$$
\log D=\log K_{l n}+l \log C_{L H}+n p H
$$

One can note that $n=0$ for ion-pair formation.

The nature of $C_{1 n}$ extracted species noted thereafter $(I, n)$ can be obtained from $\log \mathrm{D}=\mathrm{f}\left(\log C_{\mathrm{LH}} ; \mathrm{pH}\right)$ variations according to modified slops method:

$$
\left(\frac{\partial \log D}{\partial p H}\right)_{C L H}=n
$$

and

$$
\left(\frac{\partial \log D}{\partial \log C_{L H}}\right)_{p H}=l
$$

The parameters $n$ and / are varying with experimental conditions. As indicated above there is no predominant extraction reaction, that Cd extracted specie often results in combining two entities ${ }^{6-7}$. Conventional methods of slope analysis can't be performed successfully in this condition ${ }^{10 ; 13 . I n ~ t h i s ~}$ case numerical modeling procedure is performed by fitting experiment data to a polynomial equation ]

Fig. 3 shows plots of $\left(\frac{\partial \log D}{\partial p H}\right)_{C L H}=n$

and $\left(\frac{\partial \log D}{\partial \log C_{\overline{\mathrm{LH}}}}\right)_{p H}=l$ as a function of $\mathrm{pH}$. As shown, the molar ratio metal: $\mathrm{LH} \mathrm{H}_{3} \mathrm{O}^{+}$are varying continuously in extracted entities with aqueous solution acidity. Overall equilibrium constant are obtained from the origin ordinates of $\log \mathrm{D}=\mathrm{f}\left(\log C_{L H}\right)$ given by $\mathrm{A}=\log \mathrm{K}_{1 n}+\mathrm{n} \mathrm{pH}$.

From these results the extraction reaction is found to be influenced by both extractant concentration and aqueous media acidity. The mechanism of this reaction involves deprotonation in more acidic condition $(\mathrm{pH}<2)$ and for $\mathrm{pH}$ ranging from 3.4 to 4.1 . Under mild acidic medium $(\mathrm{pH} 2.2-$ 3.3) recovery proceeds entirely by no ion exchange, in all the cases, and also for $C_{L R}=0.62 \mathrm{M}$, at $\mathrm{pH}>$ 4.1. While in soft acidic conditions $(4.1<\mathrm{pH}<7)$, $\mathrm{OH}^{-}$exchange is prevalent, for $\mathrm{C}_{\mathrm{CH}}=0.026,0.052$, and $0.13 \mathrm{M}$,

\section{Evaluation of $\mathrm{KI}, \mathbf{n}$}

Table I show, as example, some overall and predominant extraction constants.

It is interesting to indicate that $/$ and $\% \mathrm{n} \%$ represent successively the ligand number involved in extracted specie, and the predominant $\mathrm{H}^{+}$or $\mathrm{OH}^{-}$exchange reactions, contributing to overall equilibrium. Thus the overall constant of extracted complex $(\mathrm{I}, \mathrm{n})$, combining for successive $(P, \mathrm{i}),\left(l^{\prime}, \mathrm{j}\right)$, and $\left({ }^{\prime}, \mathrm{i}\right)\left({ }^{\prime}, \mathrm{j}\right)$ species is given by:

$\mathrm{K}_{\mathrm{l} ; \mathrm{n}}=\left(\mathrm{K}_{\mathrm{l} ; \mathrm{n}}\right)^{(1-\mathrm{x})}\left(\mathrm{K}_{\mathrm{r}^{\prime} ; n}\right)^{\mathrm{x}}$

With l'<l'<l', l'= l' +1 , and $x=l-l$ ', and $\mathrm{K}_{\mathrm{l} ; \mathrm{n}}=\left(\mathrm{K}_{\mathrm{l} ; \mathrm{i}}\right)^{(1-\mathrm{y})}\left(\mathrm{K}_{\mathrm{l} ; \mathrm{j}}\right)^{\mathrm{y}}$

with $|\mathrm{i}|<|\mathrm{n}|<|\mathrm{j}|$ and $|\mathrm{j}|=|\mathrm{i}|+1$, and $\mathrm{y}=|\mathrm{n}|-\mid$ $\mathrm{i} \mid$ and $\mathrm{K}_{\mathrm{l} ; \mathrm{i}}=\left(\mathrm{K}_{\mathrm{l} ; \mathrm{i}}^{\prime}\right)^{(1-\mathrm{x})}\left(\mathrm{K}_{\mathrm{l} ; \mathrm{j}}^{\prime \prime}\right)^{\mathrm{x}}$

$\mathrm{K}_{\mathrm{l} ; \mathrm{j}}=\left(\mathrm{K}_{\mathrm{l} ; \mathrm{i}}^{\prime}\right)^{(1-\mathrm{x})}\left(\mathrm{K}_{\mathrm{l} ; \mathrm{j}}^{\prime \prime}\right)^{\mathrm{x}}$

$K_{l ; n}=\left(K_{l ; ;}\right)^{(1-x)(1-y)}\left(K_{l ; ; j}\right)^{y(1-x)^{\circ}}\left(K_{l^{\prime \prime} ; j}\right)^{x(1-y)}\left(K_{l^{p} ; j}\right)^{x y}$

This allows to obtain :

$\log K_{l ; n}==(1-x)(1-y) \log K_{r ; i}+y(1-x) \log K_{r^{\prime} ; j}+x(1$ $-\mathrm{y}) \log \mathrm{K}_{\mathrm{I}^{\prime} ; \mathrm{i}}+\mathrm{x}(\mathrm{y}) \log \mathrm{K}_{\mathrm{I}^{\prime \prime ;}}$

As example, the overall partition equilibrium $(2.68 ; 1.83)$ in the $\mathrm{pH}$ range 1.9 to 2 , involves successive extracted species $(2 ; 1),(2 ; 2),(3 ; 1)$, and $(3 ; 2)$. Taking into account the protonation of amino group at $\mathrm{pH}<3^{6-7}$, and percentage distribution of phosphoric complexes of cadmium versus $\mathrm{pH}^{15}$, predominant reactions combing, in this case, in overall extraction are as follows: 
The equilibrium constants for the individual reactions could be obtained from the overall equilibrium constant $\mathrm{K}_{l n}$ according to:

$$
\begin{aligned}
& (1-\mathrm{x})(1-\mathrm{y})\left(\mathrm{Cd}\left(\mathrm{H}_{2} \mathrm{PO}_{4}\right)_{N}^{(2-N)+}+H_{3} \mathrm{PO}_{4}+\left(2=l^{\prime}\right)\left(\overline{\mathrm{LH}_{2}^{+} \mathrm{X}^{-}}\right)+1 \mathrm{H}_{2} \mathrm{O}\right. \\
\leftrightharpoons & \left.\left(\overline{\mathrm{Cd}^{2}\left(\mathrm{H}_{2} \mathrm{PO}_{4}\right)_{\mathrm{N}}\left(\mathrm{H}_{3} \mathrm{PO}_{4}\right)_{2-\mathrm{N}} \mathrm{H}_{-(2-\mathrm{N})} \cdot 2\left(\mathrm{LH}_{2}^{+}, \mathrm{X}^{-}\right)}\right)+(1=\mathrm{i}) \mathrm{HO}_{3}^{+}\right) ; \mathrm{N}=1: \mathrm{K}_{21}
\end{aligned}
$$

$$
\begin{aligned}
& (1-\mathrm{x})(\mathrm{y})\left(\mathrm{Cd}\left(\mathrm{H}_{2} \mathrm{PO}_{4}\right)_{N}^{(2-N)+}+2 \mathrm{H}_{3} \mathrm{PO}_{4}+\left(2=i^{\prime}\right)\left(\overline{\mathrm{LH}_{2}^{+} \mathrm{X}^{-}}\right)+2 \mathrm{H}_{2} \mathrm{O}\right. \\
& \left.\leftrightarrows\left(\overline{\mathrm{Cd}\left(\mathrm{H}_{3} \mathrm{PO}_{4}\right)_{2} \mathrm{H}_{-2}, 2\left(\mathrm{LH}_{2}^{+}, \mathrm{X}^{-}\right)}\right)+(2=\mathrm{j}) \mathrm{HO}_{3}^{+}\right) ; \mathrm{N}=0: \mathrm{K}_{22}
\end{aligned}
$$

$$
(\mathrm{x})(1-\mathrm{y})\left(\mathrm{Cd}\left(\mathrm{H}_{2} \mathrm{PO}_{4}\right)_{N}^{(2-N)+}+\mathrm{H}_{3} \mathrm{PO}_{4}+\left(3=l^{\prime \prime}\right)\left(\mathrm{LH}_{2}^{+} \mathrm{X}^{-}\right)+\mathrm{H}_{2} \mathrm{O}\right.
$$$$
\left.\leftrightharpoons\left(\overline{\left.\mathrm{Cd}^{(} \mathrm{H}_{2} \mathrm{PO}_{4}\right)\left(\mathrm{H}_{3} \mathrm{PO}_{4}\right) \mathrm{H}_{-1}, 3\left(\mathrm{LH}_{2}^{+}, \mathrm{X}^{-}\right)}\right)+(1=\mathrm{i}) \mathrm{HO}_{3}^{+}\right) ; \mathrm{N}=1: \mathrm{K}_{31}
$$

(x) $(\mathrm{y})\left(\mathrm{CdH}_{2} \mathrm{PO}_{4}\right)_{N}^{(2-N)+}+2 \mathrm{H}_{3} \mathrm{PO}_{4}+\left(3=l^{\prime \prime}\right)\left(\overline{\mathrm{LH}_{2}^{+} \mathrm{X}^{-}}\right)+2 \mathrm{H}_{2} \mathrm{O}$

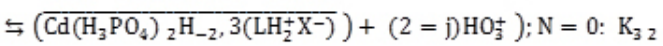

$\left(\mathrm{Cd}\left(\mathrm{H}_{2} \mathrm{PO}_{4}\right)_{N}^{(2-N)+}+(2+\mathrm{x}=l)\left(\overline{\mathrm{LH}_{2}^{+} \mathrm{X}^{-}}\right)+(\mathrm{n}=1+\mathrm{y}) \mathrm{H}_{3} \mathrm{PO}_{4}+\mathrm{n} \mathrm{H}_{2} \mathrm{O}\right.$ $\left.\leftrightharpoons \overline{\mathrm{Cd}\left(\mathrm{H}_{2} \mathrm{PO}_{4}\right)_{\mathrm{N}}\left(\mathrm{H}_{3} \mathrm{PO}_{4}\right)_{\mathrm{n}} \mathrm{H}_{-\mathrm{n}} \cdot 2\left(\mathrm{LH}_{2}^{+}, \mathrm{X}^{-}\right)}+(1+\mathrm{y}=\mathrm{n}) \mathrm{HO}_{3}^{+}\right) ; \mathrm{N}=0 ; 1: \mathrm{K}_{\mathrm{ln} .}$

The equilibrium constants for the individual reactions could be obtained from the overall equilibrium constant $\mathrm{K}_{\mathrm{ln}}$ according to:

$$
K_{L n}=\left(K_{21}\right)^{(1-x)(1-y)}\left(K_{22}\right)^{(1-x)(y)}\left(K_{31}\right)^{(x)(1-y)}\left(K_{32}\right)^{(x)(y)}
$$

and

$$
\log \mathrm{K}_{\mathrm{ln}}=(1-\mathrm{x})(1-\mathrm{y}) \log \mathrm{K}_{21}+(1-\mathrm{x})
$$

(y) $\log \mathrm{K}_{22}+(\mathrm{x})(1-\mathrm{y}) \log \mathrm{K}_{31}+(\mathrm{x})(\mathrm{y}) \log \mathrm{K}_{32}$

As example, in the case of $(2.68 ; 1.83)$ complex we have:

$$
\begin{gathered}
\log \mathrm{K}_{2.68,1.83}=(0.32)(0.17) \log \mathrm{K}_{21}+(0.32)(0.83) \log \mathrm{K}_{22} \\
+(0.68)(0.17) \log \mathrm{K}_{31}+(0.68)(0.83) \log \mathrm{K}_{32}
\end{gathered}
$$

\section{CONCLUSION}

3-methyl-2 (1H)- Methyl Quinoxaline-2thione $(\overline{\mathrm{LH}})$ is used for the extraction for cadmium from phosphoric acid $(2.5 \mathrm{M})$. This extraction is varying with initial organic ligand concentration and $\mathrm{pH}$. The stoichiometry of the extracted $\mathrm{Cd}(\mathrm{II})$ complex is varying between $1: 1: 0$ and 1:3:3: $\mathrm{Cd}$ : ${ }^{\mathrm{LH}}: \mathrm{H}_{3} \mathrm{O}^{+}$ $\left(\mathrm{OH}^{-}\right)$.

This stoichiometry was determined by a modified slope analysis. The extraction reaction is a complex process including ion exchange-ion pair formation, organic and inorganic complexation, $\mathrm{H}_{3} \mathrm{PO}_{4}$ deprotonation and solvatation phenomena. A best recovery of 43 to $60 \%$ is achieved in acidic conditions with $\mathrm{C}_{\mathrm{LH}}=0.26 \mathrm{M}$.

\section{REFERENCES}

1. Jaishankar M., Tseten T., Anbalagan N., Mathew B. B.: Toxicol. 2014, 7(2), 60-72.

2. Zhitong Y., Jinhui L., Henghua X., Conghai Y.: Procedia Environmental Sciences, 2012,16, $722-729$.

3. Ciadamidaro L., Schulin R., Madejon P. , ì Reiser R., Clucas L., Weber P., Robinson B. : Environ. Sci. Technol, 2013, 47, 4497"4504.

4. Hynek D., Krejcova L., Sochor J., Cernei N., Kynicky J., Adam V., Trnkova L. , Hubalek J. , Vrba R. , Kizek R.:Int. J. Electrochem. Sci., 2012, 7, 1802 - 1819.

5. Hubicki Z., Ko³odyñska D. : Ion Exchange
Technologies. Maria Curie-Sk3ºdowska University Poland. 2012.

6. Senhaji S. B., Elyahyaoui A. : Orient. J. Chem, 2015, 31 (3), 1601-1609.

7. Senhaji S. B., Elyahyaoui A., Saidati B., Essassi E. : IJSR, 2016, 5 (9) , 6-15.

8. Lijuan W.: B.Sc.Victoria, University of Technology Victoria, Australia, 1998

9. Romanova T.E. , Shuvaeva O.V.: Chemical Speciation \& Bioavailability, 2015, 27(3), 139145

10. Rice N.M., Smith M. R.: J. appl. Chern. Biotechnol, 1975, 25, 379-402 
11. Stewart J.A. : Rare Earth Production and Characterization Studies, University of Tennessee, Knoxville , 2015

12. NKPOZI, solvent extraction studies, University of Nigeria Nsukka, 2015

13. Onghena, Binnemans K., pure and industrial chemistry studies, University of Nigeria Nsukka, 2015-

14. Onghena and Koen Binnemans, Ind. Eng. Chem. Res, 2015, 54, 1887"1898.

15. Elyayaoui A., Boulhassa S., Guillaumont R.: Journal of Radioanalytical and Nuclear Chemistry, 1990, 142(2), 403-415 